\title{
An Exploration of Communicative Translation Strategies for Chinese Political Metaphors
}

\author{
Yuhong Huang \\ College of Humanities and Law \\ Fujian Agriculture and Forestry University \\ Fuzhou, Fujian, China \\ 47098368@qq.com
}

\author{
Ting Liao \\ School of Foreign Languages \\ South China University of Technology \\ Guangzhou, China
}

\begin{abstract}
This paper analyzes how political metaphors can be manipulated by translators in order to preserve the flavor of source texts as well as achieve intended communicative effects from the perspective of Communicative Translation Theory. Through categorizing metaphors in The Governance of China and taking the influencing factors into account, translation strategies for four quintessential types of metaphors are explored. It argues that translation strategies including domestication, conversion of metaphor to sense, omission as well as combination of literal translation and annotation are practical approaches to retain original flavor as well as obtain intended communicative effects.
\end{abstract}

Keywords-Political metaphors; Communicative translation; Ideological influence; Cultural default; Translation strategies

\section{INTRODUCTION}

Owing to the capability to convey abstract political viewpoints, elicit public emotions and guide their political orientation, metaphor serves as a persuasive device and is of great significance in constructing political and social realities. By employing tremendous metaphors, politicians succeed in communicating more effectively through addressing the latent symbolic themes residing in segments of the public consciousness or hiding facts.

Proper translation of political metaphors is a window for the world to get a glimpse of Chinese development and a channel to convey China's voice. This paper aims at exploring translation strategies for Chinese political metaphors sourced from The Governance of China from the perspective of communicative translation by taking into consideration the influencing factors such as ideology and cultural disparity.

\section{COMMUNICATIVE TRANSLATION AND POLITICAL METAPHORS}

Based on the functional theory of language proposed by Buhler and adapted by Jakobson, Peter Newmark classifies the texts into three major types: expressive, informative and vocative text. According to Newmark, the crux of expressive function has an intimate bond with the initiator of utterance, the speaker and the writer. Archetypal expressive text-types consist of serious authoritative statements, imaginative

This paper is sponsored by 2016 Fujian Education and Research Project A Study of Translator's Ethics in Publicity Translation (JAS160166) and FLTRP College English Research Project Translation Ethics in Universities' Overseas Publicity (20150016) literature as well as autobiography.

Communicative translation, one of the influential translation strategies proposed by Peter Newmark on the basis of text typology, aims at "producing on its readers an effect as close as possible to that obtained on the readers of the original" [1]. It gives priority to the "force" instead of the content of the message. It is readership-oriented and tends to under-translate and translators endeavor to reduce obscurities and exclude ambiguous interpretations.

Divergence in the mode of thinking, mapping conditions, mapping patterns as well as cultures between Chinese and English renders semantic translation of political metaphors improper in some cases. Therefore, the publicity of political ideas also requires acceptable translation for target readers to achieve desired communicative effects.

\section{POLITICAL METAPHORS IN THE GOVERNANCE OF CHINA}

Metaphor can be defined as a means allowing people to "understand one domain of experience in terms of another" [2]. While in Newmark's opinion, metaphor is composed of the "image, object and sense", and "image is the picture conjured up by metaphor and object is what is described or qualified by the metaphor, while sense is the literal meaning of metaphor" [3]. As a specific form of inference, metaphor indirectly transfers the underlying effects and communicative values of the content.

\section{A. Political writing and Metaphor: Fish and Water Relationship}

Political writing is usually an expressive text whose authority stems from "high status or the linguistic competence of their authors" [3]. The language of politics is usually culture-bound, historically conditioned and value-laden, which results in its abstraction.

In political communication, metaphors are often utilized to mystify political realities, mirror speakers' intention toward clarifying abstract and complex political realities or give an interpretation of complicated political concepts, through which politicians succeed in achieving their intention of getting ideas across or hiding facts. From the perspective of pragmatics, political metaphors also have special "added value". With the aim of obtaining support, politicians are apt to employ 
metaphors to stir public emotion and thus persuade or reassure them [4]. In essence, the application of metaphors in political sphere is not only for the expressive values but also for the persuasive virtues [5]. Thus, it is never exaggerating to say that metaphor is to politics what water is to fish.

\section{B. Categorizations of political metaphors in The Governance of China}

The Governance of China, a compilation of President Xi Jinping's major works, includes speeches, instructions, talks, etc. Composed of 18 chapters depicting various aspects of current China, it is a window for the world to better understand the Chinese government's policy and the development path of China.

Different categories of metaphors have been detected in the book The Governance of China (Table 1, and it is worth pointing out that repetitive calculation of the same metaphor is avoided). As it is shown in the table, journey metaphor accounts for the largest proportion, followed by medical metaphor, military metaphor, animal metaphor, etc. The application of these metaphors enables the translation to introduce novel mapping patterns and cultural experiences for target readers, which is in line with the waves of overseas promotion of Chinese culture and the pursuit of discursive power in international arena [6].

TABLE I. STATISTICS OF METAPHORS IN THE GOVERNANCE OF CHINA

\begin{tabular}{|c|c|c|c|}
\hline Categorizations & Frequency & Categorizations & Frequency \\
\hline Journey metaphor & 25 & Family metaphor & 5 \\
\hline Medical metaphor & 18 & Plant metaphor & 4 \\
\hline Military metaphor & 14 & Art metaphor & 3 \\
\hline Animal metaphor & 11 & Circle metaphor & 2 \\
\hline China-specific metaphor & 10 & & \\
\hline
\end{tabular}

Considering the fact that most of the journey metaphors, which is often utilized to indicate the process and path of realizing Chinese socialism, can be rendered by literal translation (such as “中国特色社会主义道路, 是实现我国 社会主义现代化的必由之路”; The path of Chinese socialism is the only way to achieve China's socialist modernization), this paper will focus on communicative translation strategies for medical metaphor, military metaphor, animal metaphor and China-specific metaphor.

\section{Medical metaphor}

"Medical metaphor is a semantic mapping from the biological domain to the social domain, which is often utilized to disclose social problems" [7]. Through medical metaphor, the exhortation of the text producer, for instance, to build up a clean Party, can be easily and directly understood by target readers. Disease, parasites and illness are quintessential types of medical metaphor. For example,

\section{（1）要抓早抓小，有病就马上治。[8]}

The important thing is to take measures to prevent and curb corruption in its earliest stage of development [9].

In this example, the source domain is disease and the target domain is corruption. The mapping is well structured by arousing the association that as disease leads to the discomfort of body, corruption exerts detrimental influence on the management of the Party. A corrupt Party is bound to fail in giving full play of its role, just as a sick body results in malfunctions of organs.

\section{Military metaphor}

Military metaphor also plays an important part in the political writing. Metaphors from military domain include strategies, flag, arm, weapon, battle, enemy, etc. For example,

(2) 批评和自我批评是……有效武器。[8]

Criticism and self-criticism is an effective weapon ... ${ }^{[9]}$

Criticism and self-criticism is considered as a weapon. A soldier can hardly achieve victory when fighting without a weapon. Likewise, the Party cannot develop well without criticism and self-criticism. It is the weapon that enhances the capability of fighting. Similarly, the Party members can unite through criticism and self-criticism.

\section{E. Animal metaphor}

Animal metaphors employed in the political language take advantage of animals' features to depict the object vividly. They endow the familiar words with new meanings in a certain context and render abstract ideas clear.

\section{(3) 防腐败要善始善终、善做善成, 防止虎头蛇尾。[8]}

We should persevere in our anti-corruption effort till we achieve final success rather than start off full of sound and fury and then taper off in a whimper [9].

In the above example, the characteristics of source domain are well projected into the target domain. “虎头蛇尾” means "in like a lion, out like a lamb". To directly and clearly convey the exhortation of speaker-coequal efforts should be put into both the beginning and the end of anti-corruption campaign, translators resort to explanation instead of literal translation. 


\section{F. China-specific metaphor}

China-specific metaphor utilizes unique figures of Chinese flavor to convey the information of image. Those figures are culture-laden and often exist exclusively in Chinese context. For example,

\section{(4) 把权利关进制度的笼子里。[8]}

Power must be "caged" by the system [9].

This China-specific metaphor occurs in the current anticorruption campaign. In the example, the system is compared to a cage which is an enclosure for confining animals. When cages are referred, people often relate them to restriction and confinement, which is a human universality; accordingly, the original image is recreated to achieve intended communicative purposes.

\section{COMMUNICATIVE TRANSLATION STRATEGIES FOR RENDERING METAPHORS IN THE GOVERNANCE OF CHINA}

The universality as well as disparities of cultures and politics requires that translation of political metaphors should be handled in various ways. Accordingly, before translation strategies are explored, it is necessary to identify the influencing factors of translating political metaphors.

\section{A. Ideology and cultural default: Two influencing factors of translating political metaphors}

Political metaphors, usually culture-bound and value-laden, are inevitably embedded with underlying ideologies and cultural uniqueness.

Ideology refers to a set of normative beliefs, conscious and unconscious ideas on which individuals base their actions. Embedded ideology in political texts serves the function of influencing public and enforcing a change. Translation is a socio-linguistic activity, and with no doubt, it can never happen in a vacuum environment, but rather influenced by certain ideological factors. Ideology, functioning as an invisible hand, manipulates the production and popularity of the translated texts. Therefore, "those ideological conflicts rooted in the psychological models and reflected in the speeches require decoding so that the voicing and stance of speakers can be understood" [10]. For instance,

(5)中国共产党是领导和团结全国各族人民……的核心 力量。[8]

The CPC is the central force for leading and bringing together people of all ethnic groups ..." [9]

In this example, the expression in italics is a circle metaphor. In China, the central government occupies the pivotal position, uniting people of all ethnic groups. Hence, there exists a latent ideological conflict. To help target readers better understand the CPC leadership, translators choose to preserve the original metaphor.

Cultural default is another factor that translators of political writings need to devote their attention to. Experiential basis of metaphors indicates that they are largely influenced by the socio-cultural environments. As a product, they are embedded with certain socio-cultural characteristics, including traditional values, customs, lifestyles, religion, etc.. "As to the crosscultural commonality of metaphors, it is subject to the degree to which metaphors stem from ubiquitous human experience which is inextricable with the specific cultures" [11]. To put it differently, though cognitive equivalence does really exist among cultures under some circumstances, more often than not translators will encounter cultural default in translation practice Therefore, translators of political writings need to devote special attention to such kind of cultural-loaded metaphors and convert them to familiar metaphors in the target language environment. For instance,

\section{(6) 工会干部是最可信赖的“娘家人”。[8]}

Trade union officials are their "family members" whom they can turn to for help [9].

In this example, “娘家人” is an expression exclusive in Chinese context, which refers to someone that individuals can depend on. With no ready metaphor in target language, explanation is indispensable for achieving intended communicative effects.

\section{B. Domestication}

Due to the disparity of culture, people in the west and China are likely to conceptualize an identical experience in varying ways. In other words, mapping conditions and mapping patterns are divergent. Although for a long time, faithfulness and accuracy are the overriding norms in the translation of political texts, while in the era of globalization, there occurs a target-oriented translation shift in Chinese political translation [12]. Therefore, to achieve the intended communicative effects among target readers, domestication can be an effective strategy.

(7) 要……扫除政法领域的腐败现象, 坚决清除害群之 马。 $[8]$

We should wipe out corruption in the judicial, procuratorial and public security fields... and remove the bad apples from them [9].

In example (7), “害群之马” is a China-specific metaphor with derogatory association, which is used by to describe corrupt members of the Party. The literal equivalent expression "black horse" cannot provide intended readers with cognitive experience due to the fact that "metaphor use is sensitive to socio-cultural context, especially to the knowledge base within an epistemic community." [13].

"Bad apple" is an idiomatic expression to describe a person whose behaviors exert corrupting influence on the rest of the group. Although "bad apple" belongs to informal expression, it is close to the colloquial style of the source text extracted from President Xi Jinping's talk. Therefore, translating “害群之 马” into "bad apple" is reader-friendly and can provide intended readers with identical emotive experience. It is easier to arouse detest to those corrupt officials and audience can understand the Party's resolution to eliminate corruption in the same way as the original readers. 
[8]

(8) 我们要坚持改革开放正确方向, 敢于啃硬骨头 ……

We will have the courage to crack the "hard nut" ...[9]

In example (8), “硬骨头” is originated from Chair Mao's On Protracted War, which means an arduous task. The literal translation of it is "hard bone", which in English means a dauntless person or unyielding integrity. It can be seen that "hard bone" is used to describe an individual or his or her spirit. However, the expression in italics in the source text refers to hardships occurring during the reform. In other words, it connects with a thing rather than an individual. Taking the above into account, literal translation is not a proper means to provide target readers with metaphorical experience.

Nevertheless, in the west, "hard nut" serves as a vehicle to metaphorically describe difficult problems. "Hard nut" is mapped onto the target domain, thus enabling audience to grasp the complication of difficulty. Translating “硬骨头” into "hard nut" is target-oriented, which provides readers with identical metaphorical meaning as that of original readers in an acceptable way.

\section{Conversion of metaphor to sense}

The translation of metaphor has an intimate bond with the conceptual system in source and target cultures. When the images in source language do not exist in target language or literal translation of metaphors renders readers perplexed, conversion of metaphor to sense is a good way to achieve intended communicative purposes.

(9) 各国不能这边搭台、那边拆台, 而应该相互补台、 好戏连台。[8]

Rather than undermining others' efforts, we should complement each other and work for joint progress. [9]

Literal translation of metaphorical expressions from one language to another is hard to produce desirable results, especially when those expressions draw on culture-specific ways of perceiving and reasoning rather than a ubiquitous schema. In the above example, the expressions in italics are China-specific metaphors which indicate that the whole world is a stage and each country is a performer. They form a systematic way of indicating national relationship in terms of competition and cooperation. "In China, traditional opera is a popular entertainment form among people, and thus it does not take them throes to understand those related expressions" [14]. However, few readers in the English-speaking countries know much about the traditional Chinese opera, and therefore those related expressions are completely unfamiliar to them. Such being the case, abandoning the original metaphors and manifesting the embedded sense is a good method to help achieve communicative effects. In this way, target readers can understand the philosophy of world peace advocated by President Xi Jinping without too much effort.
(10) 因此, 要 ……打好主动仗。对国家和民族具有重 大战略意义的科技决策，想好了、想定了就要决断。

Hence, we should ... adopt a proactive strategy. As to scientific and technological policies of great strategic value to our country and nation, we should make up our minds and act without any hesitation. [9]

In example (10), “主动仗” is a military metaphor which refers to undertaking initiatives. It is obvious that the development of science and technology is compared to a war. Those valuable strategies are supposed to be implemented without hesitation, be it in the war or scientific innovation. Any country failing in taking proactive strategies is to be left in a disadvantageous situation. "Compared with the west, military metaphors are more frequently utilized in Chinese context, and therefore literal translation of military metaphors is inclined to produce misunderstanding among western people that China is a warlike nation" [15]. Hence, the translator converts it to "proactive strategy" so that target readers can correctly seize the intention of text producer and the significance of undertaking initiatives in scientific and technological development.

\section{Omission}

Metaphors are products of a particular culture and are embedded with its uniqueness. This uniqueness derives from specific literary traditions, social customs, faith, etc. Whether a value is given priority to or not is largely a matter of the subculture one lives in. In other words, a value in a culture will be in conflict with the metaphorical structure of plausibly corresponding concept in another culture. Under such circumstance, semantic translation is apt to result in misunderstanding, let alone achieve the expected communicative effects. Hence, it is imperative for translators to delete those conflicting images. For example,

\section{(11) 坚持军事斗争准备的龙头地位不动摇, $\cdots \cdot \cdots \cdot$ [8]}

Being "action ready" must be its major task ...[9]

(12) ……坚持以军事斗争准备为龙头带动现代化建 设。[8]

...We should ... modernize our armed forces. [9]

In examples (11) and (12), “龙头” is an animal metaphor which means being in the core position. The literal equivalent word of “龙” in the west is dragon. However, no common recognition can be achieved through the vehicle “龙头” between Chinese and westerners. In western countries, "dragon" has long been a symbol of evil power, which originates from its literary tradition. However, Chinese attach diametrically opposite values to dragon. It symbolizes supreme power and relates to royalty, which deserves reverence and respect. In the case of “龙头”, a culturally constructed schema, if translated literally, there occurs a meaning shift from a rather positive to a negative notion, thus failing to achieve desired communicative effects. To avoid the cognitive conflict and misunderstanding, translators resort to 
omission of original images and deletion of the socio-cultural underpinnings of the concept.

\section{E. Combination of literal translation and annotation}

"If there is a risk that the simple transfer of the metaphor will not be understood by most readers" [1], the translator can resort to annotation on the basis of literal translation to transfer the original cultural flavor to target readers. To be more specific, the strategy of literal translation plus annotation enables target readers to transcend the chasm between cultures and grasp the uniqueness of source language culture. As an auxiliary means, annotation is a good way to preserve culturally-loaded images and the flavor of original texts. "Although in some situations annotation may be complex, it is conducive for the target readers to understand the source texts" [16]. For example,

(13) 一是坚持政治解决冲突的方向。世界上热点问题 不少，按下葫芦起了漂。[8]

First, seeking political solutions is the right path to address the seemingly endless sequence of international flashpoints. "Just when you press the gourd into the water, there floats the gourd ladle." - "Just when you press the gourd into the water, there floats the gourd ladle." is a traditional Chinese saying that means "tackling one problem only to find another emerging. " [9]

In the above example, “按下葫芦起了㼼” is a Chinaspecific metaphor. It connects natural happening with social phenomenon and the very metaphorical systematicity allows original readers to comprehend international clashes in terms of daily experience. As to such culture-specific modes of thinking rather than a shared notion or schema, literal transfer of metaphorical image may render target readers dazed. Thus, with the aim of retaining the original savor and making the ground of similarity explicit, translators resort to annotation by adding "tackling one problem only to find another emerging" in the end. Consequently, the intention of cross-cultural communication is achieved and the unique Chinese culture is well promoted.

(14) 要……坚持 “老虎”、“苍蝇”一起打。[8]

We must be tough in ...catching "tigers" and "flies" senior officials as well as junior ones guilty of corruption. [9]

In example (14), the expressions in italics are animal metaphors occurring in the current anti-corruption campaign. The experience of physiques provides a further basis for understanding the rank of offenders. To promote unique Chinese political culture and preserve the metaphorical savor, they are translated literally. The reconcilement of readers' acceptance with features of Chinese political language is a cornerstone for readability of the English translation and effective communication [17]. Therefore, translators clarify the "tigers" and "flies" by adding annotation: "senior officials as well as junior ones guilty of corruption" to make the ground of similarity explicit. In this way, the specific Chinese culture is well promoted and the resolution of the CPC Party to fight against corruption can easily be understood by target readers.

\section{CONCLUSION}

Political translation is an effective and direct approach to conveying China's voice and establishing positive images. Since metaphor counts much in the construction of political and social realities, its translation cannot be neglected. High quality translation of political metaphors requires exact transmission of metaphorical savor in the original texts; meanwhile the distinctive cultural features, emotive effects of original metaphors and ideological implication should not be ignored.

This article analyzes the translation of metaphors in The Governance of China from the perspective of communicative translation. With the aim of shedding light on Chinese political metaphor translation, several communicative translation strategies, like domestication, conversion of metaphor to sense, omission as well as combination of literal translation and annotation are proposed.

There is still room for improvement of this paper which only concentrates on translation of four types of Chinese political metaphors. There are other categories in political texts deserving analysis. In future study, the research scope will be expanded to make the conclusion more comprehensive and persuasive.

\section{REFERENCES}

[1] P. Newmark, Approaches to Translation. Shanghai, Shanghai Foreign Language Education Press, 2001, pp. 39, 90.

[2] G. Lakoff, M. Johnson, Metaphors We Live By. Chicago: University of Chicago Press, 2003, p. 117.

[3] P. Newmark, A Textbook of Translation. Shanghai, Shanghai Foreign Language Education Press, 2001, pp. 105, 39.

[4] A. Musolff. Political Metaphor Analysis: Discourse and Scenarios. New York, Continuum Publishing Corporation, 2016, p. 4.

[5] M. Mocanu. The political metaphor from expressive values to persuasive virtues, International Letters of Social and Humanistic Sciences. Switzerland, vol. 57, pp. 118-126, August 2015.

[6] L. Cao, H. Wang: English translation of metaphors with Chinese characteristics in $\mathrm{Xi}$ Jinping's speeches: from the perspective of embodied philosophy. Language and Translation, vol. 3, pp. 65-70, August 2017. (In Chinese).

[7] W. Pan, J. Zhang: Translation of sci-tech vocabulary metaphor: a case study of Selected Works of Mao Tse-tung, Chinese Science \& Technology Translators Journal, vol. 29, pp. 35-37+5, November 2016. (In Chinese).

[8] J. Xi, The Governance of China. Beijing: Foreign Languages Press, 2014 , pp. 394, 377, 387, 385, 38, 47, 150, 348, 363, 122, 216, 219, 251, 392. (In Chinese).

[9] J. Xi, The Governance of China. Beijing: Foreign Languages Press, 2014, pp. 438, 415, 428, 425, 45, 50, 167, 384, 331, 134, 238, 241, 275, 434.

[10] M. McLaughlin and J. Muñoz-Basols, Ideology, censorship and translation across genres: past and present, Perspectives: Studies in Translatology, vol. 24, pp. 1-6, January 2016.

[11] S. Tobias. Traversing textual terrains: the translation of metaphor in "rashōmon", Translation Review, vol. 92, pp. 8-22, December 2015.

[12] J. Li and S. Li, New trends of Chinese political translation in the age of globalization, Perspectives: Studies in Translatology, vol.23, pp. 424439, February 2015.

[13] Z. Schmidt and X. Peng. Winds and tigers: metaphor choice in China's anti-corruption discourse, Lingua Sinica, vol. 3, pp. 35-61, December 2017. 
[14] F. Liu, A study of C-E metaphor translation principles. BeiJing: National Defense Industry Press, 2008, pp. 90-91. (In Chinese).

[15] X. Chen: Metaphor as rhetorical discouse: C-E differences and translation. Journal of Fuzhou University (Philosophy and Social Sciences). vol. 120, pp. 85-89, March 2014. (In Chinese).

[16] R. Lin, D. Lin: Chinese-English translation of political documents: translation from a cultural perspective - exemplified by English language version of Xi Jinping: The Governance of China, Southeast Academic Research, vol. 6, pp. 235-240, November 2016. (In Chinese).

[17] Y. Zhang: On idiomaticity of English translation of Chinese political documents, Shanghai Journal of Translation, vol. 133 , pp. 30-34+93, April 2017. (In Chinese). 